\title{
The Dictyostelium discoideum model system
}

\author{
Guest Editors \\ Ricardo Escalante $^{1}$ and Elena Cardenal-Muñoz ${ }^{2}$ \\ IInstituto de Investigaciones Biomédicas "Alberto Sols" (CSIC-UAM), Madrid, Spain \\ rescalante@iib.uam.es - iD https://orcid.org/0000-0001-8547-531X \\ ${ }^{2}$ Département de Biochimie, Faculté des Sciences, Université de Genève, Sciences II, Genève, Sreitzerland \\ elena.cardenal@unige.ch - (iD https://orcid.org/0000-0003-4757-9323
}




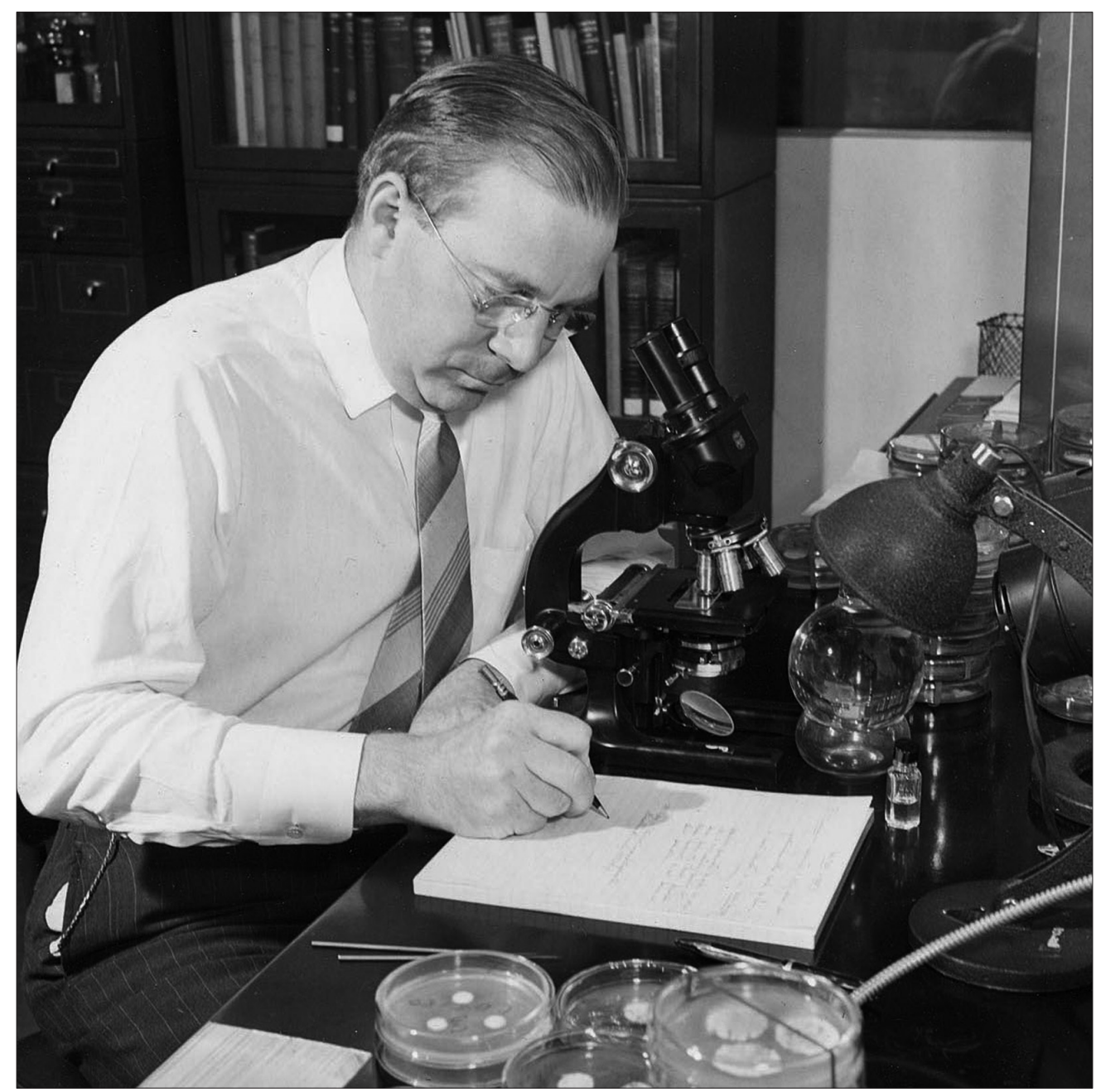

Kenneth Bryan Raper (1908-1987)

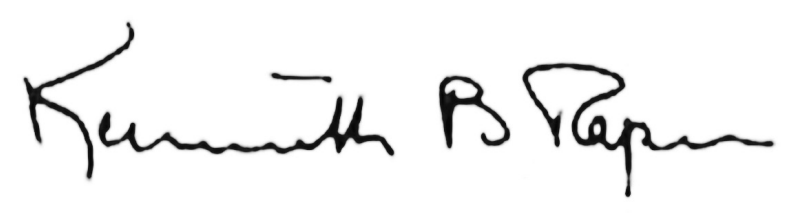

This Special Issue of The International Journal of Developmental Biology is dedicated to Kenneth Bryan Raper (19081987), who discovered Dictyostelium discoideum and described the remarkable features of this organism, setting up the basis for its use as a model system. Photo reproduced with permission from the University Archives and Records Management of the University of Wisconsin-Madison, USA. 


\section{Preface}

\section{Dictyostelium discoideum: the organism and the model}

When we set out to organize this Special Issue, we faced the difficult task of gathering together a large variety of topics with the unique commonality of having been studied in a single model organism, Dictyostelium discoideum. This apparent setback turned into a wonderful opportunity to learn about an organism as a whole, which provides a more complete understanding of life processes, their natural meaning and their changes during evolution. From studies dedicated almost exclusively to cell motility, differentiation and patterning, the versatility of $D$. discoideum has allowed in recent years the expansion of our knowledge to other areas, including cell biology and many others related to human diseases. The present collection of papers can be considered as a journey throughout the mechanisms of life, where $D$. discoideum acts as a very special tourist guide.

Social amoebas are remarkable microorganisms that live in the soil feeding on bacteria. More than 150 species dispersed world-wide have been discovered to date. One of these species, Dictyostelium discoideum (hereafter referred to as Dictyostelium) was discovered in 1933 by Kenneth Raper in the Craggy Mountains of Western North Carolina (Raper, 1935). When food becomes scarce, the Dictyostelium cells aggregate to form a simple multicellular organism of few millimeters in size. The duality of this amoeba as a single and multicellular organism is a remarkable characteristic that has attracted the interest of evolutionary biologists trying to reveal the paradigm of multicellular evolution.

The seminal works by McCutcheon (McCutcheon, 1946) in leucocytes and Bonner in Dictyostelium (Bonner, 1947) were essential to determine that these cells actually move towards chemical gradients. Since then, Dictyostelium has become a leading model to uncover the molecular mechanisms of chemotaxis. Knowing how cells recognize and signal each other before and after their aggregation is fundamental to understand how a multicellular organism organizes. How do initially equivalent cells differentiate and form developmental patterns? How do the cells communicate and interact with their environment, including interactions with other organisms such as bacteria? Dictyostelium, despite its apparent simplicity, is a valid model to answer all these questions.

As mentioned, switching from uni- to multicellularity is a remarkable characteristic of Dictyostelium. However, the striking similarity of single amoebas to animal cells, especially to those of the immune system, in comparison with the cells of plants or fungi, has contributed to the flourishing of Dictyostelium as a cell biology model. There are many examples of homologous proteins in Dictyostelium and animals that have been lost in the fungi or plant linages, despite the fact that Dictyostelium is closer in evolution to the latter. In contrast to plant and fungi, Dictyostelium and metazoan cells lack a cell wall, an absence that allows them to move by chemotaxis and feed by phagocytosis and macropynocitosis, key processes which make these amoebae more similar to animal cells. But the similarities between Dictyostelium and animal cells extend to genes and proteins that regulate other well-conserved processes such as cell division and growth, autophagy, innate immunity, mitochondrial metabolism, etc.

The gene-hunting strategy followed by an exceptional generation of open-minded scientists, including William Loomis and many others (Loomis, 1998; Sucgang et al., 2011) was fundamental in the search for genes affecting Dictyostelium's development. Loomis' path has been followed by genome analyses leading to the discovery of disease-related genes (Eichinger et al., 2005). It is fascinating to think that an amoeba could help us understand the pathological mechanisms of human diseases. But yes indeed, a growing number of disease-associated processes are now being modeled in Dictyostelium, including infection by pathogenic microbes (Steinert, 2011), disorders that affect the lysosomal, autophagy and cellular trafficking processes (Maniak, 2011; Mesquita et al., 2017), and mitochondrial diseases (Francione et al., 2011) to mention just a few examples.

Int. J. Dev. Biol. 63: 317-320 (2019)

doi: 10.1387/ijdb.190275re 
Another interesting aspect arises from the simplicity of Dictyostelium's handling in the laboratory. Its fast growth at room temperature and atmospheric $\mathrm{CO}_{2}$ levels, as well as under diverse conditions (on agar or in liquid, in static or shaking, with or without light, etc.) makes Dictyostelium ideal for teaching at any educational level, as simple and reproducible experiments can be performed with very modest settings.

There is no doubt that the potential of Dictyostelium as a model system is still far from being reached. Whether all perspectives will be fulfilled or not depends on many different factors, including the fierce competition with other systems for funding. In this regard, the support of a centralized NIH-funded resource, dictyBase and dicty stock center, that gathers, organizes and annotates all available information about Dictyostelium and stores valuable strains and plasmids is critical for the future development of this model.

This collection of reviews, written by leading scientists in their fields, is an updated overview of the research that is now being conducted with Dictyostelium. We hope that it will also serve the non-specialist readers to understand the peculiarities and commonalities of this organism with other, perhaps more popular, models. The research areas covered by Dictyostelium nowadays exceed the limits of this Special Issue. We would like to apologize for the many topics and authors that could not be well represented in this collection and acknowledge the great job of reviewers and the editors of the Int. F. Dev. Biol.

Ricardo Escalante and Elena Cardenal-Muñoz Madrid (Spain) and Geneva (Switzerland) 2019

\section{References}

BONNER JT (1947). Evidence for the formation of cell aggregates by chemotaxis in the development of the slime mold Dictyostelium discoideum. J Exp Zool 106: 1-26.

EICHINGER I, PACHEBAT JA, GLÖCKNER G, RAJANDREAM MA, SUCGANG R, BERRIMAN M, SONG J, OLSEN R, SZAFRANSKI K, XU Q, et al., (2005). The genome of the social amoeba Dictyostelium discoideum. Nature 435: 43-57.

FRANCIONE LM, ANNESLEY SJ, CARILLA-LATORRE S, ESCALANTE R, FISHER PR (2011). The Dictyostelium model for mitochondrial disease. Semin Cell Dev Biol 22: 120-130.

LOOMIS WF (1998). The Dictyostelium genome sequencing project. Protist 149: 209-212.

MANIAK M (2011). Dictyostelium as a model for human lysosomal and trafficking diseases. Semin Cell Dev Biol 22: 114-119.

MCCUTCHEON M (1946). Chemotaxis in Leukocytes. Physiol Rev 26: 319-336.

MESQUITAA, CARDENAL-MUÑOZ E, DOMINGUEZ E, MUÑOZ-BRACERAS S, NUÑEZ-CORCUERA B, PHILLIPS BA, TÁBARA LC, XIONG Q, CORIA R, EICHINGER L, GOLSTEIN P, KING JS, SOLDATI T, VINCENT O, ESCALANTE R (2017). Autophagy in Dictyostelium: Mechanisms, regulation and disease in a simple biomedical model. Autophagy 13: 24-40.

RAPER KB (1935). DICTYOSTELIUM DISCOIDEUM, ANEW SPECIES OF SLIME MOLD FROM DECAYING FOREST LEAVES. JAgric Res $50: 135-147$. STEINERT M (2011). Pathogen-host interactions in Dictyostelium, Legionella, Mycobacterium and other pathogens. Semin Cell Dev Biol $22:$ 70-76.

SUCGANG R, KUO A, TIAN X, SALERNO W, PARIKH A, FEASLEY CL, DALIN E, TU H, HUANG E, BARRY K, et al., (2011). Comparative genomics of the social amoebae Dictyostelium discoideum and Dictyostelium purpureum. Genome Biol 12(2): R20. (doi: 10.1186/gb-2011-12-2-r20). 


\section{Further Related Reading, published previously in the Int. J. Dev. Biol.}

Evidence for an evolutionary relationship between Vmp1 and bacterial DedA proteins Luis-Carlos Tábara, Olivier Vincent and Ricardo Escalante

Int. J. Dev. Biol. (2019) 63: 67-71

https://doi.org/10.1387/ijdb.180312re

Dictyostelium discoideum Sir2D modulates cell-type specific gene expression and is involved in autophagy Rakhee Lohia, Punita Jain, Mukul Jain, Pradeep Kumar Burma, Anju Shrivastava and Shweta Saran

Int. J. Dev. Biol. (2017) 61: 95-104

https://doi.org/10.1387/ijdb.160038ss

The Dictyostelium prestalk inducer DIF-1 directs phosphorylation of a bZIP transcription factor

Yoko Yamada, Yuzuru Kubohara, Haruhisa Kikuchi, Yoshiteru Oshima, Hong-Yu Wang, Susan Ross and Jeffrey G. Williams

Int. J. Dev. Biol. (2013) 57: 375-381

https://doi.org/10.1387/ijdb.130046jw

An orthologue of the Myelin-gene Regulatory Transcription Factor regulates Dictyostelium prestalk differentiation

Hiroshi Senoo, Hong-Yu Wang, Tsuyoshi Araki, Jeffrey G. Williams and Masashi Fukuzawa

Int. J. Dev. Biol. (2012) 56: 325-334

https://doi.org/10.1387/ijdb.120030jw

Bimodal distribution of motility and cell fate in Dictyostelium discoideum

Pavana Goury-Sistla, Vidyanand Nanjundiah and Gopal Pande

Int. J. Dev. Biol. (2012) 56: 263-272

https://doi.org/10.1387/ijdb.113384ps

ASET/MYND chromatin re-modelling protein regulates Dictyostelium prespore patterning Beatriz Nuñez-Corcuera, Joanna Birch and Jeffrey G. Williams

Int. J. Dev. Biol. (2011) 55: 205-208

https://doi.org/10.1387/ijdb.113309bn

Synergy between two transcription factors directs gene expression in Dictyostelium tip-organiser cells

Hong Yu Wang and Jeffrey G. Williams

Int. J. Dev. Biol. (2010) 54: 1301-1307

https://doi.org/10.1387/ijdb.103141hw

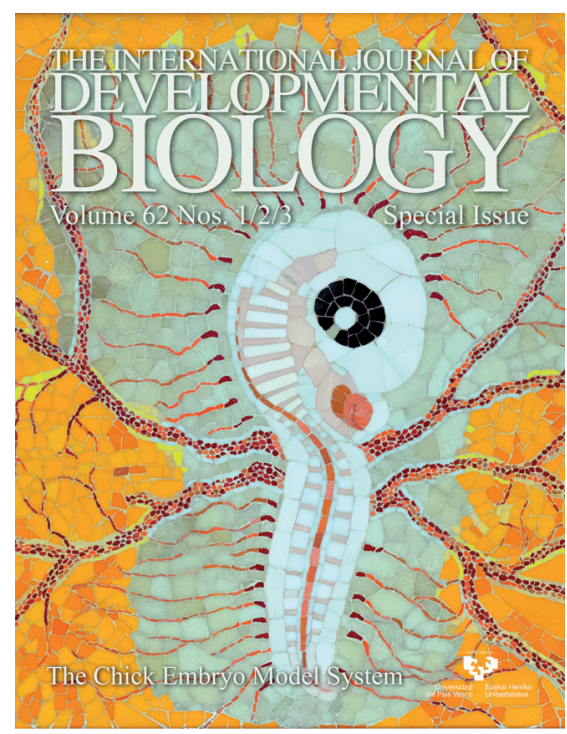

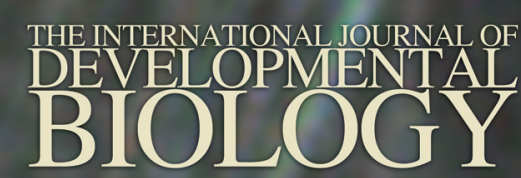

Volume 56 Nos. $1 / 2 / 3$

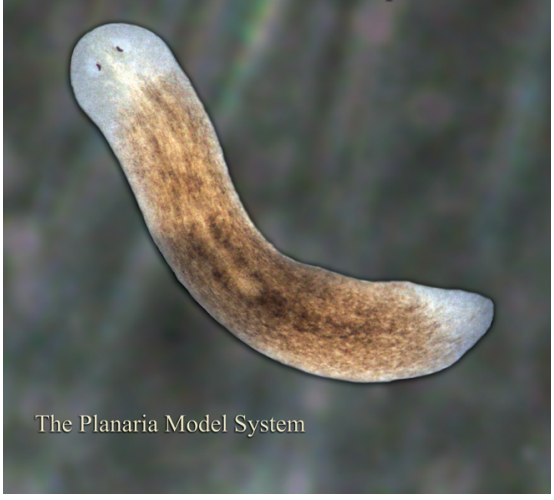

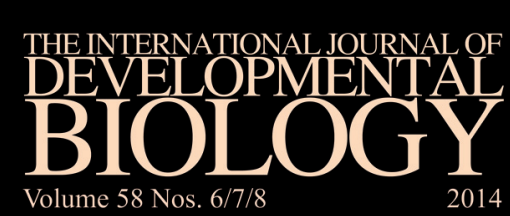

Volume 58 Nos. 6/7/8

2014

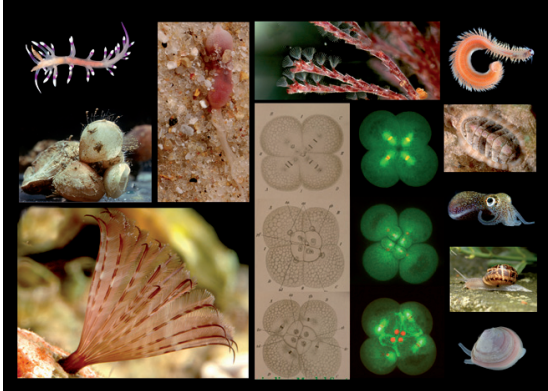

Spiralian Model Systems

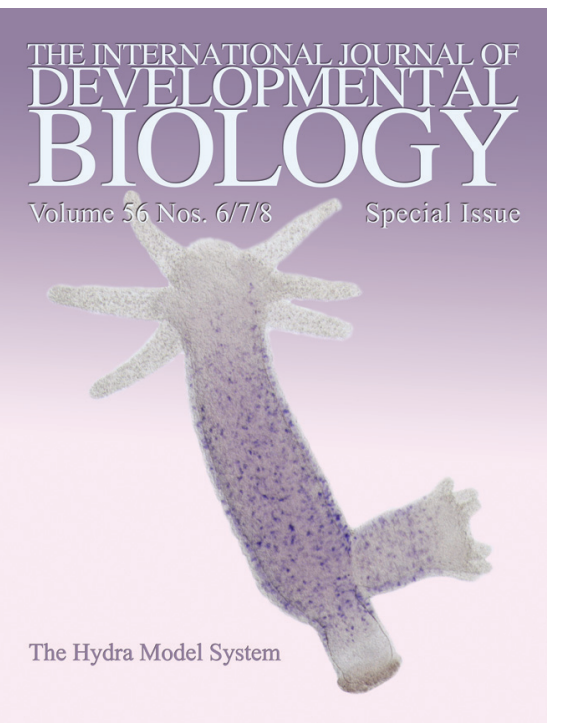

